\title{
MULTIPLE-SCALE SOIL MOISTURE DISTRIBUTION AND ITS IMPLICATIONS FOR ECOSYSTEM RESTORATION IN AN ARID RIVER VALLEY, CHINA
}

\author{
K.-M. MA, ${ }^{1,2} *$ B.-J. FU, ${ }^{1}$ S.-L. LIU, ${ }^{1}$ W.-B. GUAN, ${ }^{3}$ G.-H. LIU, ${ }^{1}$ Y.-H. Lü ${ }^{1}$ AND M. ANAND ${ }^{2}$ \\ ${ }^{1}$ Research Center for Eco-Environmental Sciences, Chinese Academy of Sciences, Beijing 100085, China \\ ${ }^{2}$ Biology Department of Laurentian University, Sudbury, Ontario P3E 2C6, Canada \\ ${ }^{3}$ Beijing Forestry University, Beijing 100083, China \\ Received 4 July 2003; Revised 23 July 2003; Accepted 30 September 2003
}

\begin{abstract}
The spatial distribution of soil moisture and its multiple-scale correlations to other environmental factors were examined along the Upper Minjiang River valley, China, a landscape subject to severe land degradation of soil and water erosion but also under investigation for potential ecosystem restoration. Results showed that: (1) Soil moisture was highest in the headwaters, and lowest in the arid valley, while moderate values characterized outside the arid valley. The polynomial model of soil moisture distribution on slopes was concave in the lightly disturbed headwaters, convex in the highly damaged arid valley, while convex on south facing slopes and concave on north facing slopes in highly damaged areas in better environmental condition. (2) Soil moisture was correlated with environmental factors at different scales, where elevation and air humidity were only correlated at the sample plot scale, light intensity and wind speed were found to be significant at both slope and site scales and slope and sample plot scales; while slope angle was correlated at all the three scales. From this we conclude that it is possible to improve soil moisture conditions in the arid valley by lowering slope angle and adding low-cost irrigation systems. (3) The practical threshold of soil moisture for growing meadows, shrubs, and forests were 11.800 per cent, 3.925 per cent, and 16.078 per cent respectively; the arid valley displayed soil-moisture conditions unfavourable to forest growth. The planned reforestation project is not ecologically reasonable. Reducing human disturbance and revegetating with natural shrubs and meadows may produce more effective results. Copyright (C) 2004 John Wiley \& Sons, Ltd.
\end{abstract}

KEY WORDS: ecosystem restoration; environmental factors; multiple scales; refforestation; soil moisture; Upper Minjiang River valley

\section{INTRODUCTION}

The negative impacts of land degradation are both ecological and socioeconomic. Human land use (such as deforestation, unsustainable agricultural practices, and overgrazing) often cause severe soil and water erosion in mountainous regions (Guan, 1996; Fu et al., 2002), which lead to ecosystem degradation and environment deterioration (Wang, 1995). These may, in turn, influence river-water quality, cause floods, lower the productivity of farmland, and enlarge the arid area. Soil and water erosion thus can have a serious impact on the local economy and social development (Wang, 1995; Wang and Xie, 1997).

\footnotetext{
${ }^{*}$ Correspondence to: Dr K.-M. Ma, Research Center for Eco-Environmental Sciences, Chinese Academy of Sciences, Beijing 100085, China. E-mail: mkm@mail.rcees.ac.cn
}

Contract/grant sponsor: The Development Plan of the State Key Fundamental Research of China (973); contract/grant numbers: 2000046807 and $2002 \mathrm{CB} 111505$.

Contract/grant sponsor: Knowledge Innovation Program of Chinese Academy of Sciences; contract/grant number: KZ CX2-405.

Contract/grant sponsor: The Elliot Lake Field Research Station, Laurentian University, Canada. 
There are several ecological and engineering ways to conserve soil and water (Wang, 1995; Guan, 1996). However, soil quality improvement has been paid more and more attention in recent years (Yang, 1993; Wang and Xie, 1997; Fu et al., 2002; Cheng and Wan, 2002). In this regard, there have been abundant studies made on soil nutrients in small catchments in relation to land degradation and development (Fu et al., 2002, and the references therein), but soil moisture has been largely neglected especially on a regional scale. This is surprising due to the fact that soil moisture is one of the most important factors in ecosystem structure and function, playing a unique role in many ecological processes. It determines tree and shrub establishment (Li and Wilson, 1998), plant canopy cover and species distribution (Barton, 1993; Duff et al., 1997; Jacqmain et al., 1999), species diversity and composition (Bratli and Myhre, 1999; Breshears and Barnes, 1999; Hutchinson et al., 1999), and plant growth rate and biomass allocation (Wang et al., 1998); it also has influence on the structure and function of microbial communities (Srivastava, 1992), as well as the function of some soil nutrients (Evans et al., 1998).

The spatial variation of soil moisture is particularly important because it determines the regional distribution of ecosystems and must be considered an important factor in land-use planning and ecological restoration. Soil moisture can vary spatially in two ways: Soil moisture can be spatially autocorrelated, in which case regional patterns can be estimated through the statistical approach of spatial kriging (Bardossy and Lehmann, 1998; Fu et al., 2002); soil moisture can also display scale variation, which becomes important when comparing local and regional distribution (Seyfried, 1998). The soil-moisture distribution is influenced by many environmental factors in a given area. These include precipitation, elevation, topographical settings, vegetation types, and other soil properties (Werling and Tajchman, 1984; Francis et al., 1986; Wilson and Kleb, 1996; Gonzalez-Hidalgo and Bellot, 1997; Famiglietti et al., 1998; Yeakley et al., 1998; Yeh and Eltahir, 1998; Breshears and Barnes, 1999; Sulebak et al., 2000; Salve and Allen-Diaz, 2001). Other climatic factors, such as wind speed and light, also influence the soil moisture although few studies have been carried out. Moreover, human land uses have the potential to affect soil moisture by altering the land cover (Fu et al., 2000; Qiu et al., 2001a,b). The spatial pattern of soil moisture is actually a result of the integration of these natural and anthropogenic factors at multiple scales.

Knowing that soil moisture is crucial to ecosystem restoration and land development in arid regions, it is vital to clearly understand several key relationships: (1) how soil moisture varies at different scales; (2) what environmental factors determine the spatial distribution of soil moisture at a certain scale; (3) the soil moisture demand of a vegetation type; and (4) how to rehabilitate ecosystems by improving the influencing factors on soil moisture at different scales. All of these aspects are essential for effective ecological planning and ecosystem management projects in arid areas.

In this paper, we study the spatial variation of soil moisture along the mountainous arid Upper Minjiang River valley, an area suffering land degradation but also identified for potential ecosystem restoration. Soil and water erosion caused by vegetation damage is the most serious impact of land degradation along the Upper Minjiang River valley. Vegetation damage along the Minjiang River has taken place for at least a thousand years, mainly along the upper valley (Editorial Board of Sichuan Vegetation, 1980; Zhang, 1992). Forest cover has decreased from about 50 per cent in the 1800 s to about 18 per cent at present, and deforestation is especially prevalent in the arid valley (Editorial Board of Sichuan Vegetation, 1980; Zhang, 1992). Consequently, serious soil erosion has occurred, further degrading soil water and nutrient conditions (He et al., 1993; Lei and Huang, 1993). This has led to difficulty in recovering natural forests at most sites (Zhang, 1992), while increasing the silt content of the Minjiang River, and thus decreasing the water quality of the Yangtze River (He et al., 1993).

Since topography, vegetation, soils, and climatic conditions are highly variable in river basins in mountainous regions (Gurtz et al., 1999), the correlations of soil moisture to other important environmental factors were examined at the scales of site, slope, and sample plot. Physical properties studied included topographical settings, elevation, light intensity at the soil surface, wind speed, air humidity and vegetation types. The study was mainly aimed at two issues: (1) what environmental factors determined the soil moisture distribution at multiple scales in the arid valley; and (2) what implications could be concluded from the study to restore the degraded ecosystems through improving soil moisture conditions. 


\section{STUDY AREA AND METHODS}

\section{Study Area}

The Minjiang River is a first-order branch of the Yangtze River (Figure 1). It is about $735 \mathrm{~km}$ in length and has an altitude range of $3560 \mathrm{~m}$. The river is not only important economically, but also ecologically in southwestern China. It has been the main water resource of the Sichuan province, determining the production of agriculture and industry of the region. The watershed is inhabited by many rare species, such as the giant panda.

Located on the transition zone from the Tibetan Plateau to the Sichuan Basin, the Upper Minjiang River basin $\left(102^{\circ} 41^{\prime}-103^{\circ} 58^{\prime} \mathrm{E} ; 30^{\circ} 44^{\prime}-32^{\circ} 24^{\prime} \mathrm{N}\right)$ refers to the part up to Dujiangyan city (named after the great irrigation work), and is about 337 kilometers in length. It is normally incised to $<1000 \mathrm{~m}$ in depth, which results in seven levels of terraces at $7 \mathrm{~m}, 15-20 \mathrm{~m}, 50-60 \mathrm{~m}, 100 \mathrm{~m}, 150-180 \mathrm{~m}, 370 \mathrm{~m}$, and $460 \mathrm{~m}$ above water level. These terraces are fragmented and distributed in small areas (Zhang, 1992). The brown forest soils in the region are rich in lime (Bureau of Agriculture and Pasturage, Office of Soil Survey, Sichuan Province, 1997).

The mountainous topography results in a large degree of vertical variation in precipitation and air temperature. Incoming radiation is normally $4.5 \times 10^{9}-5.5 \times 10^{9} \mathrm{~J} / \mathrm{m}^{2}$, and there are $1500-2000$ sunshine hours per year. The mean temperature of the hottest month (August) is higher than $18^{\circ} \mathrm{C}$, while that of the coldest month (January) is lower than $0^{\circ} \mathrm{C}$. There are $>180$ days with temperature $\geq 10^{\circ} \mathrm{C}$. Annual precipitation is between $500-850 \mathrm{~mm}$.

Regional vegetation mainly consists of small-leaf arid shrubs (elev. 1300-2200 m), broad-leaf and needle-leaf mixed forests and evergreen and deciduous broad-leaf mixed forests (elev. 2000-2800 m), Picea and Abies forests (elev. 2800-3600 m), and alpine shrubs and meadows (elev. $>3600 \mathrm{~m}$ ) (Zhang, 1992). The Upper Minjiang River valley is now dominated by some arid shrubs, especially Caryopteris spp., Sophora vrsifolia, Bauhinia spp., Ajania potaninii, Onosma spp., Selaginella pulvinata and Desmodium spp. These are accompanied by some grasses and other plants, Miscanthus sinensis, Themeda triandra, Asparagus filicinus, Setaria glauca, Aristida adscensionis, and Achnatherum inaequiglume (Editorial Board of Sichuan Vegetation, 1980).

\section{Methods}

Considering the arid valley, which is about $108 \mathrm{~km}$ long, as the key part of the study area, six sites were chosen according to the degree of degradation in terms of vegetation damage. These sites were located approximately $500 \mathrm{~m}$ apart, from the highest elevation headwaters to the lower site (Yingxiu) along the Upper Minjiang River valley (see Figure 1). Three sites were located inside the arid valley, two sites outside the arid valley, and one site at the headwaters. More specifically, the headwaters Doujitai (Site 1), was mainly covered by alpine meadow and natural forests, and was only lightly disturbed by logging and grazing. The upper site outside the arid valley, Desheng (Site 2), displayed the secondary needle-leaf forest after logging on north-facing slopes, and the dwarf dry shrubs on south-facing slopes. The upper end of the arid valley, Shidaguan (Site 3), upon which vegetation was seriously destroyed by logging and cultivation activities, had few vascular plant species, mainly short, dry grasses and dwarf, dry shrubs on both the north- and south-facing slopes. At the central part of the arid valley, Feihongguan (Site 4), vegetation consisted only of sparse dwarf, dry shrubs on the north-facing slopes and sparse vegetation on the south-facing slopes. On the lower portion of the arid valley, Wenchuan (Site 5), some trees occupied the north-facing slopes, but only sparse shrubs were present on the south-facing slopes. Finally, on the outside of the arid valley, Yingxiu (Site 6), was dominated by naturally recovering dense, small trees and high shrubs on slopes that had undergone forest cutting.

At each site, two transects were placed on the opposite south- and north-facing slopes, oriented towards the lower-elevation slope so as to make a ' $\mathrm{V}$ ' shape. Sample plots were set up on each transect according to the vegetation types (forest, shrub, and meadow). Normally, three plots were set up in each vegetation type. However, occasionally only one or two plots were feasible, particularly when the vegetation type was narrowly distributed on slope. More than three plots were sampled if the vegetation area was large enough. Knowing that soil moisture varies over time, due to fluctuations in rainfall and plant water requirements in the summer season, soil-moisture sampling was carried out on sunny days within a two-week period in August 2001 (after 3 days of no rainfall; there was only one rain event at Site 2 during the field work), in order to keep the sampling conditions similar. 


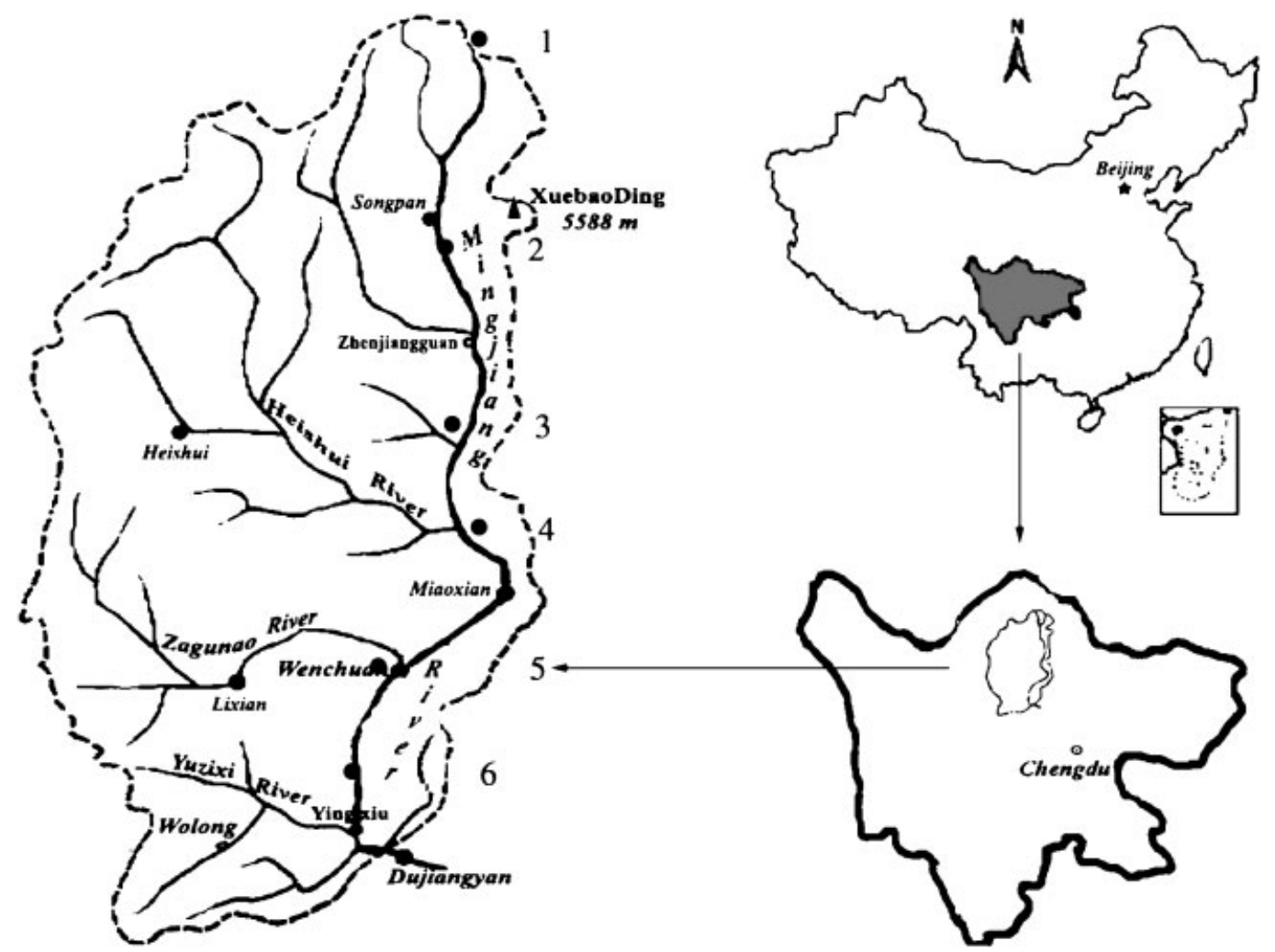

Figure 1. Location of the sample sites along the Upper Minjiang River, China. Where Sites 1 to 6 are Doujitai, Desheng, Shidaguan, Feihongguan, Wenchuan, and Yingxiu, respectively, starting from the headwaters.

Within each sample plot, the corresponding environmental factors, including elevation, topographical settings (slope, position, and aspect), light intensity at the soil surface, wind speed, and air humidity were measured when determining soil moisture. The elevation was measured using an altitude meter, the slope angle and aspect were measured using a clinometer and compass, the light intensity at the soil surface was measured using an illumination meter, wind speed was measured using an anemometer, and air humidity was measured using a psychrometer. All measurements were replicated three times. The moisture of surface soil $(0-15 \mathrm{~cm})$ was determined at nine points within each plot using a portable Time Domain Reflectometer (TDR). In total, data from 108 sample plots were collected in the field.

All the above parameters were averaged according to the 3 scales of sample plot, slope (aspects and positions), and site respectively. The soil-moisture variation of sample plots on slope was regressed using second-order polynomial models, because they provided the best fit of the data. Correlation analyses were performed between soil moisture and the other environmental factors at the three scales respectively. All the corresponding probabilities were examined according to a correlation coefficient table (Zar, 1999).

\section{RESULTS}

\section{Soil Moisture Variation along the Valley at Different Scales}

At the site-level, soil moisture was the highest at the headwaters of Site 1, and lowest in the arid valley from Sites 3 to 5, while moderate values were found outside the arid valley at Sites 2 and 6 (Figure 2a). The soil moisture within 


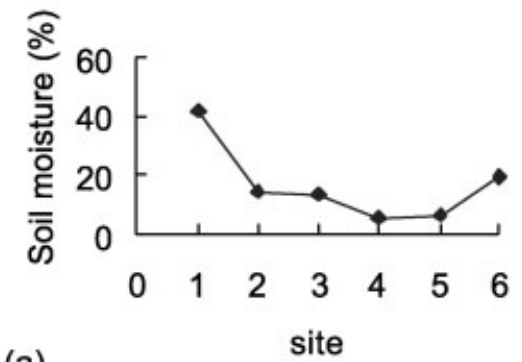

(a)

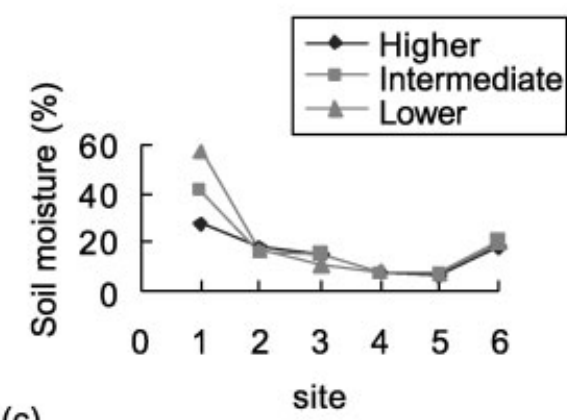

(c)

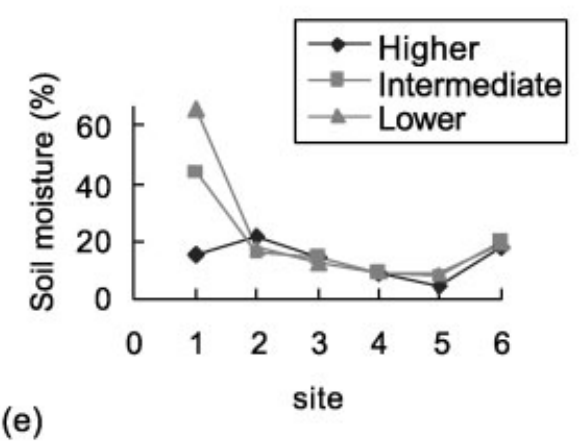

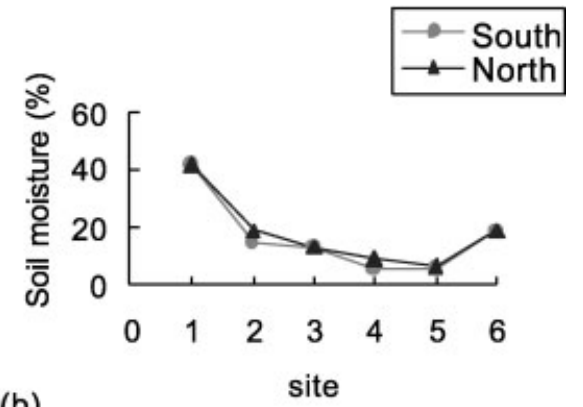

(b)

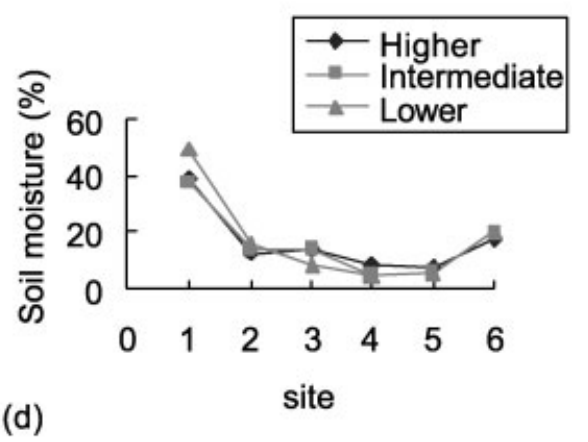

(d)

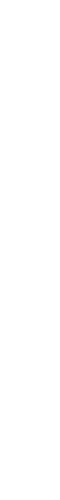


Table I. The polynomial models of the soil moisture variation of sample plots along the slopes at the six sites along the Upper Minjiang River valley. The analysis was performed from the top to the foot of each mountain

\begin{tabular}{lllll}
\hline Site & Model of south-facing slope & Response type & Model of north-facing slope & Response type \\
\hline 1 & $y=0 \cdot 446 x^{2}-3 \cdot 176 x+43 \cdot 661^{*}$ & Concave & $y=0 \cdot 389 x^{2}+6 \cdot 382 x+2 \cdot 049 * * *$ & Concave \\
2 & $y=-0 \cdot 365 x^{2}+4 \cdot 513 x+4 \cdot 244^{* *}$ & Convex & $y=3 \cdot 650 x^{2}-16 \cdot 561 x+34 \cdot 600 * * *$ & Concave \\
3 & $y=-0 \cdot 134 x^{2}+2 \cdot 059 x+8 \cdot 326^{* * *}$ & Convex & $y=0 \cdot 067 x^{2}-0 \cdot 837 x+15 \cdot 980$ & Concave \\
4 & $y=0 \cdot 225 x^{2}-2 \cdot 364 x+10 \cdot 876^{*}$ & Concave & $y=-0 \cdot 299 x^{2}+2 \cdot 090 x+6 \cdot 024 * *$ & Convex \\
5 & $y=-0 \cdot 011 x^{2}-0 \cdot 288 x+7 \cdot 467 * *$ & Convex & $y=-0 \cdot 109 x^{2}+1 \cdot 904 x+1 \cdot 768^{* * *}$ & Convex \\
6 & $y=-1 \cdot 172 x^{2}+6 \cdot 150 x+12 \cdot 378^{* * *}$ & Convex & $y=0 \cdot 342 x^{2}-1 \cdot 208 x+18 \cdot 917 * * *$ & Concave \\
\hline
\end{tabular}

$* p<0.05 ; * * p<0.01 ; * * * p<0 \cdot 001$.

elevations produced higher moisture values. Similar trends were found on north-facing slopes at all sites, with the exception of lower elevations yielding higher moisture content at the headwaters. This could indicate that the combination of slope aspect and position greatly affected soil moisture on the north-facing slope of the headwaters, but it had little influence in the arid valley.

At sample plot scale, the second-order polynomial models fitted to soil-moisture distribution along the slopes were all statistically significant except on the north-facing slope at Site 3 (Table I). This suggested a regularity that soil moisture response was concave at the headwaters, convex in the arid valley (except the south-facing slope at Site 4), convex on south-facing slopes and concave on north-facing slopes in both sites outside the arid valley. This could indicate that the soil-moisture distribution was concave on slopes in the lightly disturbed area (i.e. headwaters), but convex on slopes in the highly damaged arid valley, while convex on south-facing slopes and concave on northfacing slopes in highly damaged areas with better environmental conditions (i.e. sites outside the arid valley). The soil-moisture distribution was thus closely related to disturbance intensity and soil-moisture conditions.

\section{Multiscale Correlations of Soil Moisture with Environmental Factors}

Environmental factors were correlated with soil-moisture variation along the Upper Minjiang River valley at multiple scales (Table II). At the site scale, slope angle was correlated with soil moisture negatively $(p<0 \cdot 01)$ and light intensity at the soil surface was correlated with soil moisture positively $(p<0.05)$ among all the environmental factors. At the slope scale, three environmental factors were correlated with soil moisture. These

Table II. The correlations of soil moisture to environmental factors along the Upper Minjiang River valley at multiple scales

\begin{tabular}{|c|c|c|c|c|c|}
\hline Scale & Slope & Elevation & Light intensity & Wind speed & Air humidity \\
\hline Site & $-0.9355^{* *}$ & $0 \cdot 7190$ & $0 \cdot 8167 *$ & $0 \cdot 6900$ & $0 \cdot 6721$ \\
\hline \multicolumn{6}{|l|}{ Slope aspects } \\
\hline South-facing & $-0 \cdot 6782$ & $0 \cdot 7190$ & $0 \cdot 3679$ & $0 \cdot 6990$ & $0 \cdot 6721$ \\
\hline North-facing & -0.7774 & 0.7896 & $0 \cdot 8628 *$ & $0 \cdot 6670$ & $0 \cdot 5674$ \\
\hline \multicolumn{6}{|l|}{ Slope positions } \\
\hline Highest elevation & $-0 \cdot 5782$ & $0 \cdot 7423$ & $0 \cdot 6872$ & $-0 \cdot 2638$ & $0 \cdot 7970$ \\
\hline Intermediate elevation & $-0 \cdot 6374$ & 0.7072 & $0 \cdot 5522$ & $0 \cdot 8210^{*}$ & $0 \cdot 7888$ \\
\hline Lower elevation & $-0.9872 * * *$ & 0.7638 & 0.6636 & $0 \cdot 8608 *$ & $0 \cdot 3497$ \\
\hline \multicolumn{6}{|l|}{ South-facing slope } \\
\hline Highest elevation & $-0 \cdot 5635$ & $0 \cdot 6917$ & $0 \cdot 5723$ & $-0 \cdot 0666$ & $0 \cdot 6049$ \\
\hline Intermediate elevation & $-0 \cdot 1149$ & 0.6886 & $0 \cdot 2638$ & 0.7793 & 0.7837 \\
\hline Lower elevation & $-0.9334 * *$ & 0.7375 & $-0 \cdot 0296$ & $0 \cdot 8384 *$ & $0 \cdot 3449$ \\
\hline \multicolumn{6}{|l|}{ North-facing slope } \\
\hline Highest elevation & $-0 \cdot 3585$ & 0.4499 & $0 \cdot 2829$ & $-0 \cdot 5140$ & $0 \cdot 8030$ \\
\hline Intermediate elevation & $-0 \cdot 6507$ & 0.7227 & $0 \cdot 8921 *$ & $0 \cdot 8523 *$ & $0 \cdot 7880$ \\
\hline Lower elevation & $-0.9390 * *$ & $0 \cdot 7751$ & $0.8638 *$ & $0 \cdot 8722 *$ & $0 \cdot 3511$ \\
\hline Plot & $-0.7540 * * *$ & $0.6902 * * *$ & $0 \cdot 1972$ & $0.4176 * *$ & $0 \cdot 5261 * * *$ \\
\hline
\end{tabular}

$* p<0.05 ; * * p<0.01 ; * * * p<0 \cdot 001$. 
were slope angle, light intensity at the soil surface, and wind speed. The slope angle at lower elevations $(p<0 \cdot 001)$ was the reason for its effect at the site scale and, similarly, the north-facing intermediate and lower elevation light intensities (both $p<0.05$ ) affected the light intensity influence at the site scale. Wind speed was also correlated with soil moisture distribution at slope scale. The south-facing lower elevations and the north-facing intermediate and lower elevations correlated well $(p<0 \cdot 05)$, but this factor failed to influence soil moisture at the site scale. At sample plot scale, all the environmental factors were statistically significant correlated to soil moisture, except light intensity at the soil surface. We can summarize two facts from the above results. (1) The number of correlated environmental factors increased as the scale was decreased in the upper valley. There were two, three, and four factors correlated at the site, slope, and sample plot scales respectively. (2) The environmental factors influenced soil moisture at different scales. Two factors, elevation and air humidity, were only effective at the sample plot scale. Two factors were statistically significant at two scales, light intensity at slope and site scales and wind speed at slope and sample plot scales. Slope angle was statistically significant at all three scales. Interestingly, wind speed and light intensity at the soil surface were both positively correlated with soil moisture in the upper Minjiang River, indicating that the stronger the wind or light, the wetter the soil. This seems counterintuitive, but may be explained in this arid valley as a result of the föhn effect combined with the influence of elevation.

\section{Soil Moisture Distribution in Different Vegetation Communities}

Vegetation pattern is not only a result of soil-moisture distribution, it could also affect the soil moisture regime in an arid region. Important features from the mutual relationship between vegetation type and soil moisture can be utilized to restore the degraded ecosystem in the arid valley. The soil-moisture conditions were different in forests, shrublands, and meadows at site and slope (aspect and position) scales. At the site scale, shrublands had lower values than the other two, while forests and meadows were similar (Figure 3a). At the slope scale, results were variable. (1) Patterns were different on south- and north-facing slopes (Figure 3b). The soil-moisture regime was shrublands $<$ forests $<$ meadows on south-facing slopes, and meadows $<$ shrublands $<$ forests on north-facing slopes. (2) At different slope positions, the soil-moisture regime was meadows $<$ shrublands $<$ forests at higher elevations, shrublands $<$ meadows $<$ forests at intermediate elevations, and shrublands $<$ forests $<$ meadows at lower elevations (Figure 3c). There was no explicit pattern in the soil-moisture conditions in different vegetation communities at the slope scale.

In order to determine the practical threshold of soil moisture for forests, shrublands, and meadows in the upper valley, we summarized the field data of the sample plots by finding the lowest soil moisture for each vegetation type. This showed that the practical threshold of soil moisture were 11.800 per cent for meadows, 3.925 per cent for shrublands, and 16.078 per cent for forests respectively. Compared with the soil-moisture regimes from each site and slope scale (Figure 2), vegetation types likely to regenerate can be suggested for each location (Table III). (1) All vegetation types can be grown in Site 1 on all slopes except that the north-facing, higher elevations could not support forest growth. (2) Site 2 can support all vegetation types, however forests may not be supported on the north-facing intermediate elevation and south-facing slopes. (3) Meadows and shrublands can probably be grown in Site 3, except that the south-facing lower elevation slope can only support the growth of shrublands, and forests could not be grown at this site. (4) Sites 4 and 5 can only support growth of shrublands. (5) Site 6 can support all vegetation types.

This indicates that the arid valley (Sites 3 to 5) was too dry to grow meadows and forests, with the exception of Site 3, which usually can support meadows. The headwaters and the site outside the arid valley had abundant soil moisture for growing all vegetation types, except that forests could not be supported on the north-facing, highest elevation slope in the headwaters, which could be due to high elevation and strong winds. Site 2 was an intermediate site, but could not support forest growth on the north-facing intermediate elevation and south-facing slopes.

\section{DISCUSSIONS AND RECOMMENDATIONS}

Ecosystem restoration has been very much needed for preserving soil and water along the upper Minjiang River valley, especially in the arid valley, although it is very difficult. The arid valley is an area where evaporation 

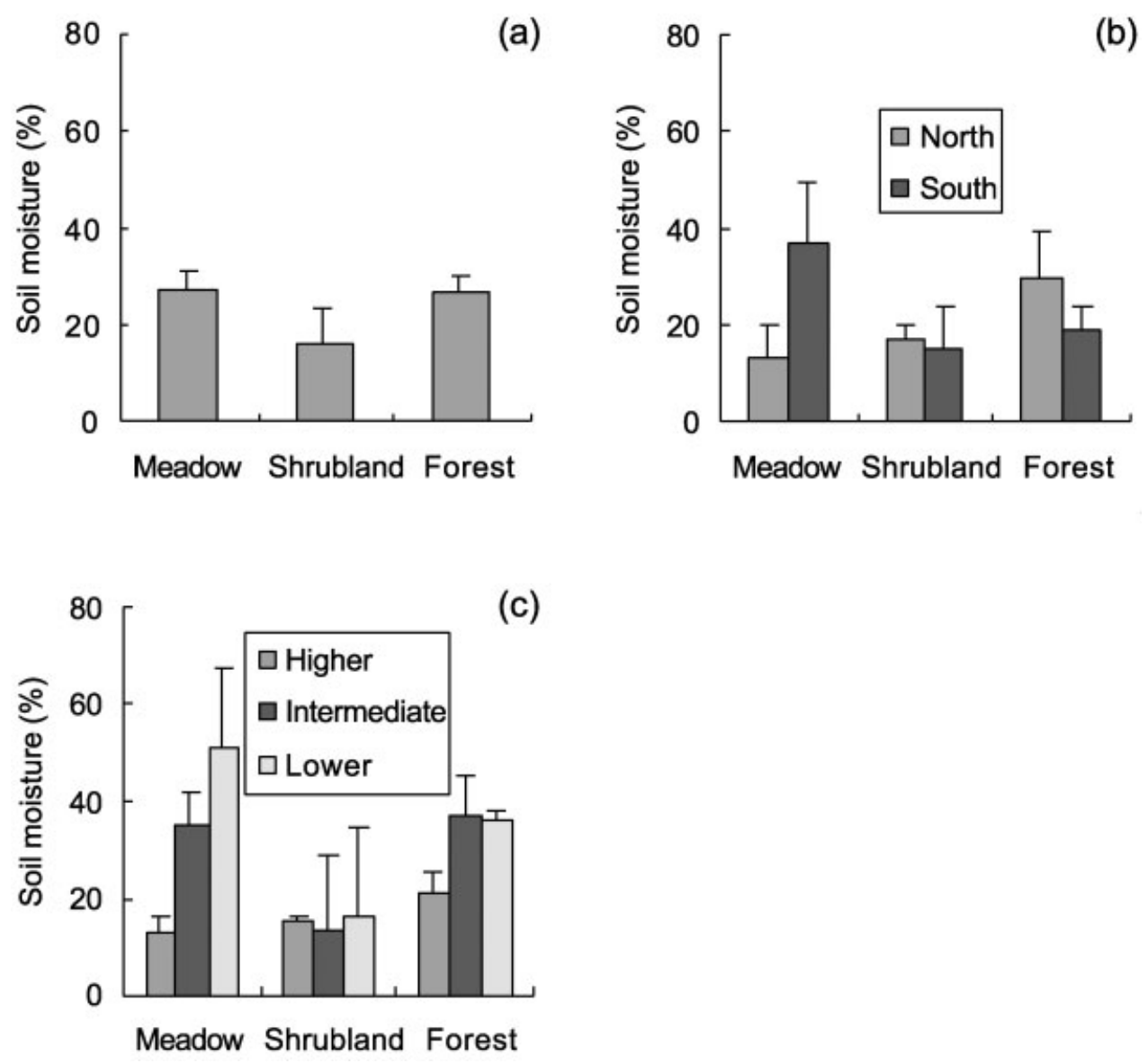

Figure 3. Soil moisture of different vegetation types in the Upper Minjiang River valley. (a) The soil moistures of meadows, shrublands and forests averaged across the sample plots within a certain vegetation type in the valley. (b) The averaged values of meadows, shrublands and forests on south- and north-facing slopes. (c) The averaged values of meadows, shrublands and forests on higher, intermediate and lower elevation slopes.

$\left(>1500 \mathrm{~mm} \mathrm{yr}^{-1}\right)$ greatly exceeds precipitation $\left(500 \mathrm{~mm} \mathrm{yr}^{-1}\right)$. Meanwhile, the climate in the arid valley, as a result of the föhn effect, results in lower areas of the valley becoming even drier than the higher slopes. This has become a further impediment to forest recovery in the lower areas. Many zonal species are difficult to establish under the insufficient water conditions present following forest clear-cutting, especially on the steep south-facing slopes, which are mainly covered by sparse, dwarf shrublands with small, hard or needle leaves. Meanwhile, species sensitive to the disturbances in the region also led to habitat fragmentation and the endangerment of rare species such as the giant panda (Liu et al., 2001; Loucks et al., 2001). Hence, the Minjiang River has been considered one of the most important watersheds in China for ecological restoration and biological conservation under the background of land degradation. In recent years, the Chinese Government has made great efforts in facing these problems (Zhang et al., 2000).

This empirical study showed that soil moisture is an important factor to characterize land degradation, and a crucial factor in ecosystem restoration and reforestation in the arid valley of the Minjiang River, its multiple-scale distribution and correlation to other environmental factors provided some valuable implications for regional reforestation and land development. These could also be significant in other places experiencing similar problems throughout the world. 
Table III. Vegetation types that can be supported along the Upper Minjiang River valley under given soil-moisture thresholds. The practical thresholds of soil moisture are 11.800 percent for meadows (M), 3.925 percent for shrublands (S), and 16.078 per cent for forests $(\mathrm{F})$

\begin{tabular}{lcccccc}
\hline Scale & Site 1 & Site 2 & Site 3 & Site 4 & Site 5 & Site 6 \\
\hline $\begin{array}{l}\text { Site } \\
\text { Slope aspects }\end{array} \quad$ M, S, F & M, S, F & M, S & S & S & M, S, F \\
$\quad$ South facing & & & & & & \\
$\quad$ North facing & M, S, F & M, S & M, S & S & S & M, S, F \\
$\begin{array}{l}\text { Slope positions } \\
\quad \text { Highest elevation }\end{array}$ & M, S, F & M, S, F & M, S & S & S & M, S, F \\
$\quad$ Intermediate elevation & M, S, F & M, S, F & M, S & S & S & M, S, F \\
$\quad$ Lower elevation & M, S, F & M, S & M, S & S & S & M, S, F \\
South facing slope & M, S, F & M, S, F & S & S & S & M, S, F \\
$\quad$ Highest elevation & & & & & & \\
$\quad$ Intermediate elevation & M, S, F & M, S & M, S & S & S & M, S, F \\
$\quad$ Lower elevation & M, S, F & M, S & M, S & S & S & M, S, F \\
North facing slope & M, S, F & M, S & S & S & S & M, S, F \\
$\quad$ Highest elevation & & & & & & M, S, F \\
Intermediate elevation & M, S & M, S, F & M, S & S & S & M, S, F \\
Lower elevation & M, S, F & M, S & M, S & S & S & M, S, F \\
\hline
\end{tabular}

Past efforts at ecosystem restoration and reforestation were not satisfactory, because soil moisture as a critical variable was not taken into account. The ecological principle of 'restoring suitable vegetation in the right place' has been put forward for the reforestation in the arid valley for many years (The Integrated Investigation Group for Upper Minjiang River, 1979, unpublished work), and the central government conceived this idea before implementing its 'Green for Grain' policy ( $\mathrm{Li}, 2001)$. Historically, many places inside the arid valley have been reforested, even in recent years after the 'Green for Grain' policy was put in place. Under these circumstances, two kinds of problem occurred. (1) Reforestation in the arid valley was very costly. More money was invested in planting tree seedlings, and irrigation became necessary for the seedlings to obtain water upslope from the Minjiang River to ensure that the moisture demands of the plants could be met. (2) Tree seedlings that have survived may die in the future due to low soil moisture. Trees in other arid areas have been found to overuse soil water in the deep layers (Lu, 1997). This not only slows down the growth of the trees, but also can lead to mortality and the inability to revegetate the site in the future. Therefore, we urgently need to change the present manner of reforestation techniques towards that of natural recovery.

Specifically, soil moisture has been considered the most limited factor in the ecosystem restoration along the Upper Minjiang River valley (He et al., 1993). Our study showed that soil moisture was very low in the arid valley (Sites 3-5) and sufficient for recovering natural forests outside the area (Sites 1, 2 and 6) (Figure 2). We can restore forests in all the disturbed sites outside the arid valley except on the south-facing slopes in Site 2, but we may only be able to restore shrublands and some meadows rather than forests inside the arid valley (as a result of the soilmoisture conditions). Our results strongly support the notion that we should implement ecosystem restoration strictly according to the soil-moisture distribution in the region. This would be necessary for two reasons: (1) Recovering shrublands and meadows in the arid valley would be at a lowest cost, since it is a natural process; and (2) as the goal of ecological restoration has been changed from forestry production to environmental improvement in the region, we need not reforest in a single step. The shrub and meadow restoration could more effectively prevent the soil and water losses in the region (Liu, 2003), which would gradually improve the physical conditions for future forest planting and recovery as implied by this study. Moreover, the regional ecosystem restoration along the arid valley should be planned according to the multiple-scale distribution of soil moisture, as shown in this study, which would be more effective in regional land-development practice as well.

Besides strictly implementing the principle of 'restoring suitable vegetation in the right place' in the ecological restoration along the arid valley under natural environmental conditions, we may also be able to accelerate 
ecosystem restoration directly by improving the soil moisture in some possible sites through engineering methods. Among all the correlated environmental factors at different scales, lowering slope would be the only possible way for increasing soil moisture. This can be accomplished by altering the shape of the steep slope to terrains and dams (Bao and Chen, 1999). Contour planting on slopes can also be useful in aiding soil and water conservation, and this has often been employed in mountainous farming practices (Chow et al., 1999). Irrigation is probably the best way of improving soil moisture conditions for vegetation recovery and restoration, however it can only be implemented when water resources are convenient (i.e. close) and the cost is low.

Knowing that land degradation is not only an ecological, but also an economic and social problem, some relevant conservation policies are needed to reduce human disturbance on these lands. These policies could include forbidding forest clear-cutting, returning farmland in unsuitable places to natural vegetation, and preventing other activities that might cause vegetation damage and soil and water loss. Actively, some alternative industries also need to be established in the region. Small water power plants and ecological tourism are examples of industries that have been developed with success in recent years (Lü, 2003).

However, this empirical study was only concerned with the spatial pattern of soil moisture, since we were interested in the spatial scales of moisture distribution. Of course, the temporal variation of soil moisture is equally important to ecosystem restoration, and further study on spatiotemporal soil-moisture distribution, while much more intensive, may be needed to supply a better answer to the questions surrounding regional ecological restoration in the arid river valley.

\section{ACKNOWLEDGEMENTS}

Thanks to Mrs Yongxiang Kang, Jianyun Zhou, Tao Lu, Yuxin Zhang, Chunhua Xie, Jianan Wu, Rongjin Yang, Yilong Huang, and Zhilin Huang for generous help in the field investigation and Steve Kaufman for editorial assistance in English.

\section{REFERENCES}

Bao WK, Chen QH. 1999. Study on the restoration and rehabilitation of the degraded mountain ecosystem. Journal of Mountain Science 17(1): 22-27 (in Chinese).

Bardossy A, Lehmann W. 1998. Spatial distribution of soil moisture in a small catchment. Part 1: geostatistical analysis. Journal of Hydrology 206(1-2): 1-15.

Barton AM. 1993. Factors controlling plant distributions: drought, competition, and fire in montane pines in Arizona. Ecological Monographs 63(4): 367-397.

Bratli H, Myhre A. 1999. Vegetation-environment relationships of old hay meadows at Sverveli, Telemark, S Norway. Nordic Journal of Botany 19(4): 455-471.

Breshears DD, Barnes FJ. 1999. Interrelationships between plant functional types and soil moisture heterogeneity for semiarid landscapes within the grassland/forest continuum: a unified conceptual model. Landscape Ecology 14(5): 465-478.

Bureau of Agriculture and Pasturage, Office of Soil Survey, Sichuan Province, 1997. Soil of Sichuan. Science and Technology Press of Sichuan: Chengdu (in Chinese).

Cheng JM, Wan HE. 2002. Vegetation Construction and Soil and Water Conservation of Loess Plateau. China Forestry Press: Beijing (in Chinese).

Chow TL, Rees HW, Daigle JL. 1999. Effectiveness of terraces/grassed waterway systems for soil and water conservation: a field evaluation. Journal of Soil and Water Conservation 54(3): 577-583.

Duff GA, Myers BA, Williams RJ, Eamus D, O'Grady A, Fordyce IR. 1997. Seasonal patterns in soil moisture, vapour pressure deficit, tree canopy cover and pre-dawn water potential in a northern Australian savanna. Australian Journal of Botany 45(2): 211-224.

Editorial Board of Sichuan Vegetation. 1980. Sichuan Vegetation. People's Publishing House of Sichuan: Chengdu (in Chinese).

Evans CA, Miller EK, Friedland AJ. 1998. Nitrogen mineralization associated with birch and fir under different soil moisture regimes. Canadian Journal of Forest Research 28(12): 1890-1898.

Famiglietti JS, Rudnicki JW, Rodell M. 1998. Variability in surface moisture content along a hillslope. Journal of Hydrology 210(1-4): 259_ 281.

Francis CF, Thornes JB, Romero-Diaz A, Lopez-Bermudez F, Fisher GD. 1986. Topographic control of soil moisture, vegetation cover and land degradation in a moisture stressed Mediterranean environment. Catena 13(2): 211-225.

Fu BJ, Chen LD, Ma KM, Zhou HF, Wang J. 2000. The relationships between land use and soil conditions in the hilly area of the loess plateau in northern Shaanxi, China. Catena 39(1): 69-78.

Fu BJ, Chen LD, Qiu Y, Wang J, Meng QH. 2002. Land Use Structure and Ecological Processes in the Hilly and Gully Region of Loess Plateau. Commerce Press: Beijing (in Chinese). 
Gonzalez-Hidalgo JC, Bellot J. 1997. Soil moisture changes under shrub cover (Rosmarinus officinalis) and cleared shrub as response to precipitation in a semiarid environment: stemflow effects. Arid Soil Research and Rehabilitation 11(2): 187-199.

Guan JW. 1996. Principles of Soil and Water Conservation. China Forestry Press: Beijing (in Chinese).

Gurtz J, Baltensweiler A, Lang H. 1999. Spatially distributed hydrotope-based modelling of evapotranspiration and runoff in mountainous basins. Hydrological Processes 13(17): 2751-2768.

He YC, Zhong XH, Zhang N, Li LH. 1993. Basic laws of water and soil loss and the construction of protection forests in the Upper Reaches of the Changjiang River. In Researches on the Chuanjiang Protection Forests in the Upper Reaches of the Changjiang River, Yang YP (ed.). Science Press: Beijing; 143-157 (in Chinese).

Hutchinson TF, Boerner REJ, Iverson LR, Sutherland S, Sutherland EK. 1999. Landscape patterns of understory composition and richness across a moisture and nitrogen mineralization gradient in Ohio (USA) Quercus forests. Plant Ecology 144(2): 177-189.

Jacqmain EI, Jones RH, Mitchell RJ. 1999. Influences of frequent cool-season burning across a soil moisture gradient on oak community structure in longleaf pine ecosystems. American Midland Naturalist 141(1): 85-100.

Lei XZ, Huang LL. 1993. A study of features of soil erosion in part of the areas along the upper reaches of the Changjiang River. In Researches on the Chuanjiang Protection Forests in the Upper Reaches of the Changjiang River, Yang YP (ed.). Science Press: Beijing; 158-166 (in Chinese).

Li X, Wilson SD. 1998. Facilitation among woody plants establishing in an old field. Ecology 79(8): 2694-2705.

Li YC. 2001. The Technical Modes for the 'Green for Grain' Policy. China Forestry Press: Beijing (in Chinese).

Liu JG, Linderman M, Ouyang ZY, An L, Yang J, Zhang HM. 2001. Ecological degradation in protected areas: the case of Wolong Nature Reserve for giant pandas. Science 292: 98-101.

Liu SL. 2003. Environmental Effects of Land Use/Cover in Representative Regions in Upper Minjiang River, China. PhD Thesis, Chinese Academy of Sciences: Beijing (in Chinese).

Loucks CJ, Lü Z, Dinerstein E, Wang H, Olson DM, Zhu C, Wang D. 2001. Giant panda in a changing landscape. Science $294: 1465$.

Lü YH. 2003. Comprehensive Decision Making on Biodiversity Conservation and Regional Development within the County Level. PhD Thesis, Chinese Academy of Sciences: Beijing, China (in Chinese).

Lu ZF. 1997. The Ecological Agriculture on the Loess Plateau of China. Shannxi Science and Technology Press: Xi'an (in Chinese).

Qiu Y, Fu BJ, Wang J, Chen LD. 2001a. Spatial variability of soil moisture content and its relation to environmental indices in a semi-arid gully catchment of the Loess Plateau, China. Journal of Arid Environments 49: 723-750.

Qiu Y, Fu BJ, Wang J, Chen LD. 2001b. Soil moisture variation in relation to topography and land use in a hillslope catchment of the Loess Plateau, China. Journal of Hydrology 240(3-4): 243-263.

Seyfried M. 1998. Spatial variability constraints to modeling soil moisture at different scales. Geoderma 85(2-3): 231-254.

Srivastava SC. 1992. Microbial C, N and P in dry tropical soils: seasonal changes and influence of soil moisture. Soil Biology and Biochemistry 24(7): 711-714.

Sulebak JR, Tallaksen LM, Erichsen B. 2000. Estimation of areal soil moisture by use of terrain data. Geografiska Annaler Series A-Physical Geography 82A(1): 89-105.

Wang JR, Hawkins CDB, Letchford T. 1998. Relative growth rate and biomass allocation of paper birch (Betula papyrifera) populations under different soil moisture and nutrient regimes. Canadian Journal of Forest Research 28(1): 44-55.

Wang LX, Xie MS. 1997. The Hydrological and Ecological Effects of Soil and Water Conservation of Mountain Protection Forest and Its Information System. China Forestry Press: Beijing (in Chinese).

Wang LX. 1995. The Science of Soil and Water Conservation. China Forestry Press: Beijing (in Chinese).

Werling JA Jr, Tajchman SJ. 1984. Soil thermal and moisture regimes on forested slopes of an Appalachian watershed. Forest Ecology and Management 7(4): 297-310.

Wilson SD, Kleb HR. 1996. The influence of prairie and forest vegetation on soil moisture and available nitrogen. American Midland Naturalist 136(2): 222-231.

Yang YP. 1993. Researches on the Chuanjiang Protection Forests in the Upper Reaches of the Changjiang River. Science Press: Beijing (in Chinese).

Yeakley JA, Swank WT, Swift LW, Hornberger GM, Shugart HH. 1998. Soil moisture gradients and controls on a southern Appalachian hillslope from drought through recharge. Hydrology and Earth System Sciences 2(1): 41-49.

Yeh PJF, Eltahir EAB. 1998. Stochastic analysis of the relationship between topography and the spatial distribution of soil moisture. Water Resources Research 34(5): 1251-1263.

Zhang PC, Shao GF, Zhao G, Le Master DC, Parker GR, Dunning JB Jr, Li QL. 2000. China's forest policy for the 21st century. Science 288: 2135-2136.

Zhang RZ. 1992. The Arid Valleys of the Hengduan Mountains Region. Science Press: Beijing (in Chinese).

Zar JH. 1999. Biostatistical Analysis, 4th edn. Simon \& Schuster/A Viacom Company: New Jersey. 